\title{
A Survey of the Public Awareness on Environmental and Public Health Laws in Ebonyi State Nigeria
}

\author{
Chinyere Ogah $^{1^{*}} \quad$ Chioma V. Iteshi ${ }^{2} \quad$ Chukwuma M. Anyigor ${ }^{3}$ \\ 1.Department of Public and Private Law, Faculty of Law, Ebonyi State University, P.M.B 053, Abakaliki, \\ Nigeria \\ 2.Department of Commercial and Industrial Law, Faculty of Law, Ebonyi State University, P.M.B 053, \\ Abakaliki, Nigeria \\ 3.Department of Industrial Chemistry, Faculty of Science, Ebonyi State University, P.M.B 053, Abakaliki, \\ Nigeria
}

\begin{abstract}
The level of environmental degradation caused by human activities can no longer be absorbed by the environment. This has weighed negatively on the environment of which man is part of. For over decades ${ }^{1}$, there has been some unfolding scenario of national efforts at industrialization, increase in the upstream and downstream sectors of the oil industry and problems associated with consumption pattern of the populace in their overall interactions with matters of public health and environmental laws ${ }^{2}$. In an effort to checkmate the excesses of man that degrades the environment and encourage those aspects of man's life that promotes a healthy environment and prevents diseases, environmental and public health laws were enacted. Regrettably, none of these laws have properly addressed environmental abuse and its related problems. This research therefore aimed at identifying the level of awareness on the existing environmental and public health laws in Nigeria particularly in Ebonyi State. To achieve this, a survey research method was adopted for this study. A total of 800 respondents comprising 500 stakeholders in the environmental and public health sectors, 200 employees of environmental and public health workers and 100 law enforcement agents were randomly selected from different geo-political zones that make up the state. Data collection was done using a self structured questionnaire titled Environmental and Public Health Laws Awareness Questionnaire (EPHLAQ) comprised of 15 question items. Data collected was analyzed using a four-scaled likert with criterion acceptance mean of 2.0. Findings revealed that the level of awareness on the existing environmental and public health laws in Nigeria particularly in Ebonyi state is very low and sanctions imposed on the defaulters of the environmental and public health laws were inadequate. Moreover, there is lack of resource to adequately address awareness need by the environmental and public health workers, health information technicians and the law enforcement agencies. It is therefore recommended among others, a heightened awareness on the existing environmental and public health laws in every sector of the economy, particularly in Ebonyi State, increase in human and material resources to adequately address awareness need in Nigeria and in particular, Ebonyi State and stiffer penalties imposed on offenders to deter intending defaulters.
\end{abstract}

Keywords: Survey, Public Awareness, Environmental and Public Health Laws.

DOI: $10.7176 / \mathrm{JLPG} / 110-06$

Publication date:June $30^{\text {th }} 2021$

\subsection{Introduction}

The fundamental relationship between environmental protection and public health is intrinsically interlocking and a complex one. Humans play a larger role in the spread of diseases than they realize through other factors over which they have some control. For example, development projects, large scale resource extraction activities, land use changes resulting from logging, agriculture and urbanization. ${ }^{3}$ These dangers posed by man to his environment and the doomsday predictions of man's deleterious activities were succinctly presented by a legal scholar thus;

God was hesitant in his creation of human beings because man was created last. The hesitation is now manifestly justified. All other creations of God sustained her intrinsic priority, peace and beauty without any violence destruction, but man has persistently dealt ruthlessly with his environment at the detriment of his and other creations survival on earth. ${ }^{4}$

\footnotetext{
${ }^{1}$ Since the Nigerian Civil War which ended in 1970, Oil activities have increased in Nigeria and these activities has led to Pollution, depleted the Ozone layer, and ultimately global warming.

${ }^{2}$ Bola Ajibola, "The Protection of the Nigerian Environment through Law" in F. Shyllon (ed).the Law and Environment in Nigeria (Ibadan Vantage) Publisher 1989 P.7

${ }^{3}$ Mare Lappe, Evolutionary Medicine: Rethinking the Origin of Diseases (San Francisco: Sierra Club Books, 1994) cited in E. Anne Platt, Infecting Ourselves: How Environment and Social Disruption 1992 among others.

${ }^{4}$ Bola Ajibola Opcit
} 
This view was in agreement with the biblical presumption that God ensured that a good environment was put in place for mankind even before the creation of man and without this, man might possibly not have been created $^{1}$. The effect of the environment on the well being of man seems to create a frightening picture of near catastrophe. A report ${ }^{2}$ disclosed that 4 million infants and children die yearly from diarrhea diseases in developing countries largely due to contaminated food or water.

Moreover, the uncontrolled discharge of domestic and municipal waste affects water, soil and food quality and this has been the major problem of environmental pollution. These made the industrialized countries of the world face mainly problems of environmental pollution caused by chemical and physical agents and in Nigeria; oil production has raised pollution to its peak ${ }^{3}$. It was in an attempt to sanitize the environment and to protect public health that emphasis was placed not just on the survival of man on this earth but also on the survival of his environment or ecosystem. This is so because the environment absorbs the waste products of our civilization through its air, soil and waste system which serves as life support with the assistance of a conducive atmosphere, availability of biodiversity and health requisites. Thus, these lead to the enactment of plethora of law of wit, environmental and public health laws. In spite of these laws, the level of public awareness on their existence is still below ebbs.

There is generally lack of enthusiasm towards the concept of enforcement of the existing environmental and public health laws both at the urban and rural areas of Nigeria; moreover, there is low response of both the government and the concerned stake holders. This necessitated this research to close the gap of low awareness on the existence of Environmental or public health laws in Nigeria particularly in Ebonyi State.

\subsection{Materials and Methods}

This section of the research discussed the materials, method and design used for the study. A survey research design was used for this study. This design is well suited for the study because it collects detailed description of existing phenomena with the intent of employing data generated from a sample selected to represent a population to justify the current condition. Moreover, this design allows the use of questionnaire or interview to collect data from a sample selected to represent a population on which findings of the data analysis can be generalized.

\subsection{Area of the study}

This study was carried out in Ebonyi state which is located in the south-eastern part of Nigeria. It was created in 1996 and was carved out of the old Abakaliki division of Enugu state and the old Afikpo division of Abia state. Ebonyi state has a population estimated at 2,504,100 based on 2011 projections. The population is homogenous, predominantly Igbos. The state capital is Abakaliki. Ebonyi state has three senatorial zones comprising of Ebonyi North, Ebonyi South and Ebonyi Central. The state is also made up of thirteen local government areas and 64 development centers.

\subsection{Population of the study}

The population of the study is made up of all the stakeholders in the environmental and public health sectors of the state totaling 800 respondents comprised of 500 stake holders in environment and public health sectors, 200 employees of environmental and public health workers and 100 law enforcement agents. The sampling technique used was a simple random sampling and they include stakeholders in Environmental and Public Health Sector of the State, Public Health Worker and Law enforcement agents totaling 800 respondents selected to represent the population. The instruments used for the study were only primary. A self-structured questionnaire with four likert scale and 15 question items were administered to the respondents. Both open and closed ended questions were included in the questionnaire to obtain appropriate responses from the respondents. To establish its validity and reliability, the structured questionnaire was reviewed by experts in the area of study and pre-tested for comprehension and clarity. A sample of 20 respondents were selected randomly from the population of the study for the pre-test and the result yielded a reliability coefficient indicating that the instruments were reliable. The data collected were analyzed using descriptive and inferential statistical technique.

\subsection{Data presentation and Analysis}

In presenting and analyzing data collected from the respondents used for the study, descriptive statistics were presented as frequency tables and items that scored mean value of 2.00 and above were accepted as positive response and therefore were significant. Results were also presented based on the research questions that guided the research. Each table from the three tables used for data presentation contains five research questions and are

\footnotetext{
${ }^{1}$ Genesis 2:4

21992 United Nation's Environmental Programme (UNEP) Report Corroborated by the World Health Organization (WHO) Commission on Health and Environment.

${ }^{3}$ Emphasis mine in view of the level of Environmental pollution in Niger Delta areas are other Oil producing State which has rendered their water useless and their farm land uncultivated
} 
thus presented.

3.1 Table 1 showing extent of public Awareness of Environmental and public health laws in Ebonyi State.

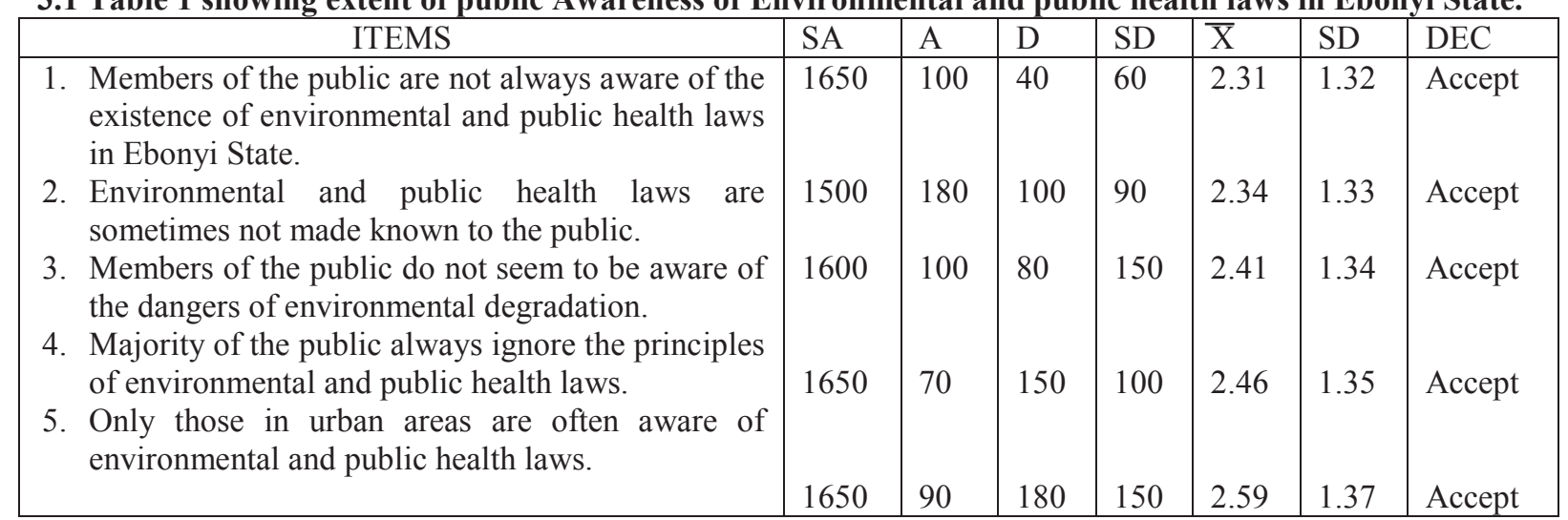

3.2 Table II showing extent of enforcement of the environmental and public health laws by the law enforcement agents and other environmental stake holders in Ebonyi State.

\begin{tabular}{|c|c|c|c|c|c|c|c|}
\hline ITEMS & SA & $\mathrm{A}$ & $\mathrm{D}$ & SD & $\bar{X}$ & SD & DEC \\
\hline $\begin{array}{l}\text { 1. Law enforcement agents always punish } \\
\text { defaulters of environmental and public health } \\
\text { laws }\end{array}$ & 1520 & 150 & 100 & 80 & 2.31 & 1.32 & Accept \\
\hline $\begin{array}{l}\text { 2. Law enforcement agents and the } \\
\text { environmental stakeholders sometimes do not } \\
\text { prosecute offenders or defaulters of } \\
\text { environmental and public health laws. }\end{array}$ & 1600 & 120 & 110 & 60 & 2.36 & 1.33 & Accept \\
\hline $\begin{array}{l}\text { 3. Enforcement of environmental and public } \\
\text { health laws in Ebonyi State is relatively poor. } \\
\text { 4. Law enforcement agents and the }\end{array}$ & 1550 & 150 & 80 & 150 & 2.41 & 1.34 & Accept \\
\hline $\begin{array}{l}\text { environmental stakeholders play partiality in } \\
\text { the enforcement of these laws in the state. } \\
\text { 5. People are sometimes not conscious of the } \\
\text { existence and enforcement of environmental } \\
\text { and public health laws in Ebonyi State. }\end{array}$ & 1600 & 120 & 150 & 100 & 2.46 & 1.35 & Accept \\
\hline
\end{tabular}

3.3 Table III showing factors that militates against the awareness of environmental and public health laws in Ebonyi State.

\begin{tabular}{|l|l|l|l|l|l|l|l|}
\hline \multicolumn{1}{|c|}{ ITEMS } & SA & A & D & SD & X & SD & DEC \\
\hline $\begin{array}{l}\text { 1. } \\
\text { Shortage of manpower often hinders } \\
\text { effective awareness of the environmental } \\
\text { and public health laws in Ebonyi State. }\end{array}$ & 1520 & 180 & 70 & 30 & 2.25 & 1.31 & Accept \\
2. $\begin{array}{l}\text { Lack of government support sometimes } \\
\text { makes it difficult to create awareness on the } \\
\text { existing environmental and public health } \\
\text { laws in Ebonyi State. }\end{array}$ & 1500 & 150 & 120 & 50 & 2.28 & 1.32 & Accept \\
3. $\begin{array}{l}\text { Shift of power in government usually affect } \\
\text { the level of awareness in environmental and } \\
\text { public health laws in Ebonyi State. }\end{array}$ & 1500 & 180 & 90 & 100 & 2.34 & 1.33 & Accept \\
$\begin{array}{l}\text { 4gnorance of the people on the dangers of } \\
\text { environmental degradation militates against } \\
\text { the awareness of environmental and public } \\
\text { health laws in the state. }\end{array}$ & 1600 & 80 & 150 & 100 & 2.41 & 1.34 & Accept \\
$\begin{array}{l}\text { 5iversion of funds provided for } \\
\text { environmental and public health law affects } \\
\text { the level of awareness in the state. }\end{array}$ & 1700 & 70 & 100 & 100 & 2.46 & 1.35 & Accept \\
\hline
\end{tabular}

\subsection{DISCUSSION OF FINDINGS AND RESULT}

The findings of this research are discussed in line with the research questions that guided the research and results presented at the end of each discussion. 
1. Extent of public awareness on the existing environmental and public health laws in Ebonyi state:

From the result presented in table 1 of this study, it was discovered that items number 1-5 with the mean scores of $2.31,2.34,2.41,2.46$, and 2.59 were all accepted that there is low awareness on the existing environmental and public health laws in Ebonyi State. The standard deviation of developments of 1.32-1.37 indicates that the reaction of the respondents did not deviate significantly.

2. Extent of enforcement of environmental and public health laws by law enforcement agents and other environmental stakeholders:

The result of the respondents in table II showed that items number 1-5 with the mean scores of 2.31, 2.36, 2.41, 2.46, 2.59 were all accepted that the law enforcement agents and other environmental stakeholders in Ebonyi state are not responsive to their duties of enforcement of environmental and public health laws in Ebonyi state. The standard deviation of developments of 1.32-1.37 indicates that the reaction of the respondents did not deviate significantly.

3. Factors that militate against public awareness of Environmental and Public Health laws in Ebonyi State

The results of the respondents in table III showed that items number 1-5 with the mean scores of 2.25, 2.28, 2.34, 2.41, and 2.46 were all accepted on the grounds that there are many factors militating against the effective enforcement of environmental and public health laws in Ebonyi state. The standard deviation ranges from (1.311.35) which indicates that the attitudes of the respondents are significant.

\subsection{Conclusion and Recommendations}

Despite the existence of enormous environmental and public health laws in Nigeria and other regional and international instruments adopted to sanitize the environment and eliminate environmental health challenges in Nigeria particularly in Ebonyi state, environmental degradation has continued to generate unpleasant challenges to human health and economic development for lack of awareness on the existing laws. These are clearly the outcome of human activities in his quest for development which has led to deforestation, pollution, population problems, poverty, inadequate water supply, environmental degradation, pollution amongst others which ultimately has led to global warming and climate change.

Unfortunately, deadly diseases have been linked with these unhealthy environmental and public health practice.

Enactments of conscious policies are regulations to checkmate man's excesses on the environment have been on the increase and have gone a long way to solving some environmental related problems in Nigeria. Notwithstanding these, the finding of the research revealed that little has been done in the area of awareness on the existing laws to the public. The environmental and public health stake holders are not always aware of existing laws and some repealed laws on the areas. Moreover, enforcement which is part of awareness are poorly financed and the agencies find it difficult to persecute offenders. In some cases where prosecution is successful, penalties are often low. This does not discourage offenders. Thus, making it impossible to achieve environmental sanity which will place the country at per with other third world countries.

To address the problems identified in this area of study the following recommendations were made.

1. There should be heightened awareness through media in both private and public sectors of the country particularly in Ebonyi State on the existing environmental and public health laws and assess to justice. This would assist to return environmental justice to the country.

2. There is need to improve in both legal and institutional framework by widening the scope of existing laws, enactment of new laws and establishment of more institutions to accommodate new environmental issues. These would go a long way to solving environmental and public health problems in Nigeria and Ebonyi State in particular.

3. There should be a review of penalties and increased punishment and charges to serve as deterrence to other intending defaulters. This would serve as a strong method of reducing violation.

4. There should be increase in both human and material resources by the government to actually address awareness need.

5. Since environment and health is interwoven, environmental education should be incorporated in the school curriculum just like health education from basic to tertiary level. This would help people to be informed of the system of the environmental protection.

Dr(Mrs) C.C Ogah is a senior lecturer Department of Public and Private Law Faculty of Law Ebonyi State University and a member of Nigerian Bar Association Onueke Branch, Nigeria. Dr Ogah is a long-standing lawyer and academic with over 17 years lecturing experience.

Dr(Mrs) C.V Iteshi is a lecturer Department of Commercial and Industrial Law, Faculty of Law Ebonyi State University. She is a member of Nigerian Bar Association Onueke Branch, Nigeria. Dr Iteshi is a long-standing Lawyer and academic with over 15 years lecturing experience.

Dr Chukwuma Michael Anyigor is an environmental chemistry and engineering expert with over 10 years 
research and lecturing experience. My academic qualifications include a Bachelor of Chemical Engineering (Nigeria), an MSc in Applied Process Control and a PhD in Chemical and Environmental Engineering both from Newcastle University UK. 